\title{
Comparison of cytotoxicity of black phosphorus nanosheets in different types of fibroblasts
}

Su-Jin Song ${ }^{1 \dagger}$, Iruthayapandi Selestin Raja ${ }^{2 \dagger}$, Yu Bin Lee ${ }^{1}$, Moon Sung Kang ${ }^{1}$, Hee Jung Seo ${ }^{1}$, Hyun Uk Lee ${ }^{3}$ and Dong-Wook $\operatorname{Han}^{1 *}$ (D)

\begin{abstract}
Background: Two-dimensional black phosphorus nanosheets (BPNSs) have recently emerged as a successive novel nanomaterial owing to their uniqueness in optical and electrical properties. Although BPNSs have found a wide range of biomedical applications, their biosafety is still a major concern to be addressed.

Methods: In this study, we have prepared layered BPNSs using liquid exfoliation procedure, and evaluated their physicochemical properties using Fourier Transform-infrared (FTIR) spectroscopy, Raman spectroscopy, atomic force microscopy, and Zetasizer analyses. We have investigated potential cytotoxicity of BPNSs against three different types of fibroblast cells, i.e. mouse embryonic fibroblast (NIH3T3), primary cultured normal human dermal fibroblast (nHDF), and fibrosarcoma (HT1080). Cell counting kit-8 (CCK-8) assay was carried out to assess cellular metabolic activity in cells whereas lactate dehydrogenase (LDH) activity assay was helpful to study plasma membrane integrity.
\end{abstract}

Results: Our salient research findings showed that BPNSs were polydispersed in solution due to aggregation. Toxic response of BPNSs against fibroblast cells was in the order, HT1080>nHDF>NIH3T3. The nanosheets reduced the number of cancerous cells with significant difference to normal cells.

Conclusions: We suggest that BPNSs can be considered for cancer treatment as they destroy cancerous cells effectively. However, a comprehensive study is required to elucidate other biological effects of BPNSs.

Keywords: Black phosphorus nanosheets, Fibroblasts, Cytotoxicity, LDH assay

\section{Background}

Over the last few decades, the development of nanoscience and nanotechnology has made dramatic progress in research fields towards the understanding of nanomaterials and the production of effective nanomaterials at large scale. Recently, black phosphorus nanosheets (BPNSs) have got attention among the researchers due to their outstanding performances in various areas including electronics, photonics, energy storage, and nanomedicine [1,2]. They have been promising candidates in biomedical fields such as drug

\footnotetext{
* Correspondence: nanohan@pusan.ac.kr

†'Su-Jin Song and Iruthayapandi Selestin Raja contributed equally to this work.

'Department of Cogno-Mechatronics Engineering, College of Nanoscience \& Nanotechnology, Pusan National University, Busan 46241, South Korea Full list of author information is available at the end of the article
}

delivery, bioimaging, biosensor, and tissue regeneration $[3,4]$. BPNSs loaded cisplatin and oxaliplatin agents were studied for in vitro evaluation of targeted drug delivery, which led to efficacy in cancer treatment [5]. An excellent near-infrared (NIR)-photoresponsive composite was fabricated with shape memory performance and biodegradability using piperazine-based polyurethane and BPNSs. The composite enabled the development of smart implantable devices, which can be controlled by the remote NIR light to alter its functions in the body [6]. However, it is of paramount importance to evaluate the toxicity profile of BPNSs to achieve numerous effective nanomaterials with biocompatibility.

BPNS is composed of only one element with sixmembered rings bound together by van der Waals force. It was reported that the elemental atoms in BPNSs are

(C) The Author(s). 2019 Open Access This article is distributed under the terms of the Creative Commons Attribution 4.0 International License (http://creativecommons.org/licenses/by/4.0/), which permits unrestricted use, distribution, and 
not connected by $\mathrm{sp}^{2}$-type bonding and each sheet is uniquely puckered by two chemically bonded double layers $[1,7,8]$. Besides the 2D layered structure, ultrafine black phosphorus quantum dots were also reported to exhibit unique electronic and optical properties owing to the quantum confinement and edge effects. A flexible memory device exhibiting a nonvolatile rewritable memory effect with a high ON/OFF ratio was fabricated by mixing black phosphorus quantum dots with polyvinylpyrrolidone. The quantum dots prepared by a facile topdown approach possessed a lateral size of $4.9 \pm 1.6 \mathrm{~nm}$ and a thickness of $1.9 \pm 0.9 \mathrm{~nm}$ [9]. Biodegradable BPQDs/PLGA nanospheres were prepared by loading black phosphorus quantum dots (BPQDs) into poly(lactic-co-glycolic acid) (PLGA) by an oil-in-water emulsion solvent evaporation emulsion method. The in vitro and in vivo characterizations demonstrated that the BPQDs/ PLGA nanospheres were biocompatible proving excellent photothermal therapy efficiency and tumor targeting ability [10].

The other known allotropes of phosphorus are white and red phosphorus. Though white phosphorus has been reported to be toxic like cyanide, red phosphorus has been found safe for human beings. The chronic exposure of white phosphorus induced several ailments such as bone necrosis, upper respiratory tract irritation, nasal discharge, and headache $[8,11]$. Some research findings showed that BPNSs with small thickness and size have high reactivity towards oxygen and water and degrades in an aqueous medium. Further, the final degradation products are phosphate and phosphonate, which are found nontoxic in the human body [10]. Meanwhile, few literature are available to demonstrate the toxicity profile of black phosphorus with convincing evidences. The cytotoxicity of BPNSs to human lung carcinoma epithelial cells (A549) was investigated after $24 \mathrm{~h}$ exposure of cells at different concentrated nanomaterials, i.e. 0$400 \mu \mathrm{g} / \mathrm{mL}$. Cell viability measurements such as watersoluble tetrazolium salt (WST-8) and methyl thiazolyl diphenyl tetrazolium bromide (MTT) assays revealed that BPNSs reduced cell viability in a dose-dependent manner. At $50 \mu \mathrm{g} / \mathrm{mL}$ of nanoparticles, the percentage of cell viability was 48 and $34 \%$ for WST- 8 and MTT assays, respectively [8]. In another study, in vitro cytotoxicity measurements of BPQDs revealed that the nanoparticles exhibited significant apoptotic effects on HeLa cells at a high concentration of $200 \mu \mathrm{g} / \mathrm{mL}$. The in vivo investigations in BPQDs exposed mice indicated that the nanoparticles could induce oxidative stress, DNA damage, and reduction of catalase activity transiently but recover to healthy state gradually [12].

In the current study, we have prepared BPNSs using a modified ultra-sonication-assisted solution method and characterized the sample using FTIR, AFM, and
Zetasizer measurements. We have demonstrated cytotoxicity of BPNSs exposing three different types of cells i.e., mouse embryonic fibroblast (NIH3T3), primary cultured normal human dermal fibroblast (nHDF), and human fibrosarcoma cells (HT1080). The experiment was carried out at various concentrations of nanosheets from 0 to $125 \mu \mathrm{g} / \mathrm{mL}$ and at different time $24 \mathrm{~h}$ and $48 \mathrm{~h}$. Also, we have investigated enzymatic activity and membrane damage in cells to assess the toxic level by CCK- 8 and LDH assays. In brief, the work aims to carry out a preliminary toxicity study to show the possible hazardous effects of BPNSs before taking them for a wide range of biomedical applications in the future.

\section{Methods}

Fabrication of black phosphorus nanosheets

BPNSs were prepared from the bulk black phosphorus material using liquid exfoliation procedure, as described in previous literature [3]. In brief, $0.4 \mathrm{~g}$ of BP nanomaterial was dispersed in a $100 \mathrm{~mL}$ of distilled water and subsequently, ultrasound sonication was carried out at $20 \mathrm{kHz}$ frequency for $30 \mathrm{~min}$. The resulting severallayered BPNSs were diluted to 10 times and ultrasonication was repeated until they produce small-sized nanosheets. The fine powder of BPNSs was obtained after drying the sample in open air for $24 \mathrm{~h}$. Before each characterization, the sample was agitated by ultrasonication for $15 \mathrm{~min}$ in distilled water to avoid agglomeration.

\section{Characterization of BPNSs}

The physicochemical properties of BPNSs were evaluated using different characterizations including Fourier transform-infrared spectrum (FT-IR, Nicolet Co., Madison, WI, USA), Raman spectrum (Micro Raman PL Mapping System, Dong Woo Optron Co., Kwangju, Korea), Atomic force microscope (AFM, NX10, Park Systems Co., Suwon, Korea), and Zetasizer (Malvern Instruments, Nano ZS, Worcestershire, UK) analyzes. FTIR spectrum attenuated with total reflection mode was recorded for the sample (BPNSs) setting the wavelength range to $4000-500 \mathrm{~cm}^{-1}$ at a resolution of $4.0 \mathrm{~cm}^{-1}$. The topography of nanosheets was observed using respective AFM image, which was further analyzed using XEI software (Park Systems Co., Seoul, Korea). The average hydrodynamic size and zeta potential of nanosheets was determined using a Zetasizer.

\section{Cell culture}

To determine the cytotoxicity of BPNSs in suspension, three different types of cells were investigated for the study. NIH3T3 fibroblast cells and nHDF normal human dermal primary cultured fibroblast cells were cultured in Dulbecco's modified Eagle's Medium (DMEM, Welgene, 
Daegu, Korea) with a high glucose concentration containing $10 \%$ fetal bovine serum (FBS, Welgene) and 1\% antibiotic-antimycotic solution (Abs, Sigma-Aldrich., Saint Louis, MO, USA). HT1080 fibrosarcoma cells were cultured in Minimum Essential Medium (MEM, Welgene, Daegu, Korea) with 10\% FBS and 1\% Abs. The cells were stored in a humidified 96-well plate with a density of $5 \times 10^{3}$ cells per well and incubated for 3 days. The cultured cells were treated with various concentrations of BPNSs $(0-125 \mu \mathrm{g} / \mathrm{mL})$ for $24 \mathrm{~h}$ and $48 \mathrm{~h}$. After $24 \mathrm{~h}$ incubation period, the change in cellular morphology by the treatment of nanosheets was monitored using an optical microscope (Leica DMIL, Leica Microsystem, Wetzlar, Germany).

\section{Cytotoxicity of BPNSs}

Measurement on cytotoxicity of BPNSs was carried out using two different assays, they are CCK-8 and LDH activity. For CCK-8 assay, CCK-8: DMEM (1:10) solution was dispensed into each well of cell plate containing the cells and samples. Absorbance was measured at $450 \mathrm{~nm}$ with ELISA Reader (SpectraMax 340, Molecular Device Co., Sunnyvale, CA) after incubation of solution mixture at $37^{\circ} \mathrm{C}$ for $2 \mathrm{~h} 30 \mathrm{~min}$ in the dark. According to LDH assay, a $60 \mu \mathrm{L}$ of reaction mixture containing catalyst (diaphorase/NAD+), dye solution of iodotetrazolium chloride and sodium lactate was transferred to the cell plate, which was preincubated with the cells and samples. Incubation was continued for $30 \mathrm{~min}$ at $25^{\circ} \mathrm{C}$ in the dark and subsequently, absorbance was measured at $490 \mathrm{~nm}$ with ELISA Reader. The control was the cell line without the addition of samples $(0 \mu \mathrm{g} / \mathrm{mL})$. The experiment was repeated three times and the data were represented with standard deviation. Data were analyzed by one-way analysis of variance (ANOVA) followed by the Tukey test and significant difference compared to control was denoted at three levels using Origin 8 software analysis $\left(" * p<0.05,{ }^{* * *} p<0.01,{ }^{* * * * *} p<0.001\right)$.

\section{Results}

\section{Spectral analyses}

FT-IR spectrum of BPNSs has displayed a stretching vibration of the $\mathrm{P}-\mathrm{O}$ bond around $1000 \mathrm{~cm}^{-1}$, as shown in Fig. 1a. The bands that appeared at $1100 \mathrm{~cm}^{-1}$ to 1600 $\mathrm{cm}^{-1}$ have been ascribed to the stretching vibration of the $\mathrm{P}=\mathrm{O}$ bond. The bending and stretching vibrational modes of $\mathrm{OH}$ have been reflected at $2400 \mathrm{~cm}^{-1}$ to 3000 $\mathrm{cm}^{-1}$, respectively. According to Raman spectrum (Fig. 1b), the nanosheet has shown three prominent peaks at $354 \mathrm{~cm}^{-1}, 433^{-1}$ and $462 \mathrm{~cm}^{-1}$, which can be attributed to $\mathrm{A}_{\mathrm{g}}^{1}$ (out of plane mode), $\mathrm{B}_{2 \mathrm{~g}}$, and $\mathrm{A}_{\mathrm{g}}^{2}$ (inplane modes), respectively.

\section{Morphology of BPNSs}

The morphology of the BPNSs has been observed from the AFM image as shown in Fig. 2a. The nanosheets appeared in aggregated form as the sample was air dried over the matrix. The corresponding height profile of BPNSs (Fig. 2b) describes that each aggregate has several layers ranging from $5.7-12.5 \mathrm{~nm}$ in size. Figure $2 \mathrm{c}$ and $\mathrm{d}$ reveal that hydrodynamic size and zeta potential of nanosheets have been $916 \pm 185 \mathrm{~nm}$ and $-20 \pm 4 \mathrm{mV}$, respectively. The polydispersion index value of nanosheets has been $0.7 \pm 0.4$.

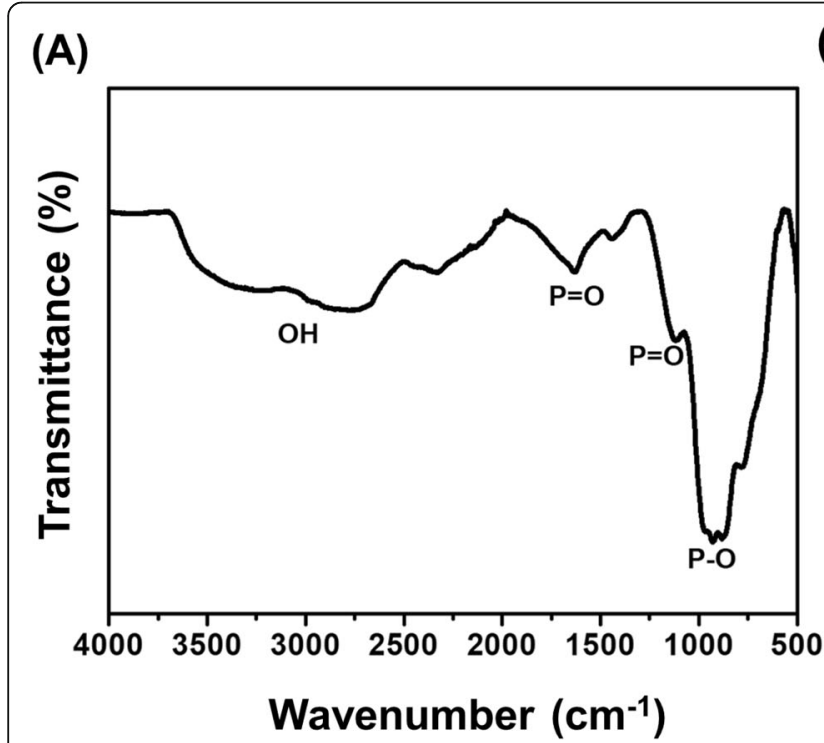

(B)

Fig. 1 a FT-IR and $\mathbf{b}$ Raman spectrum of black phosphorus nanosheets (BPNSs)

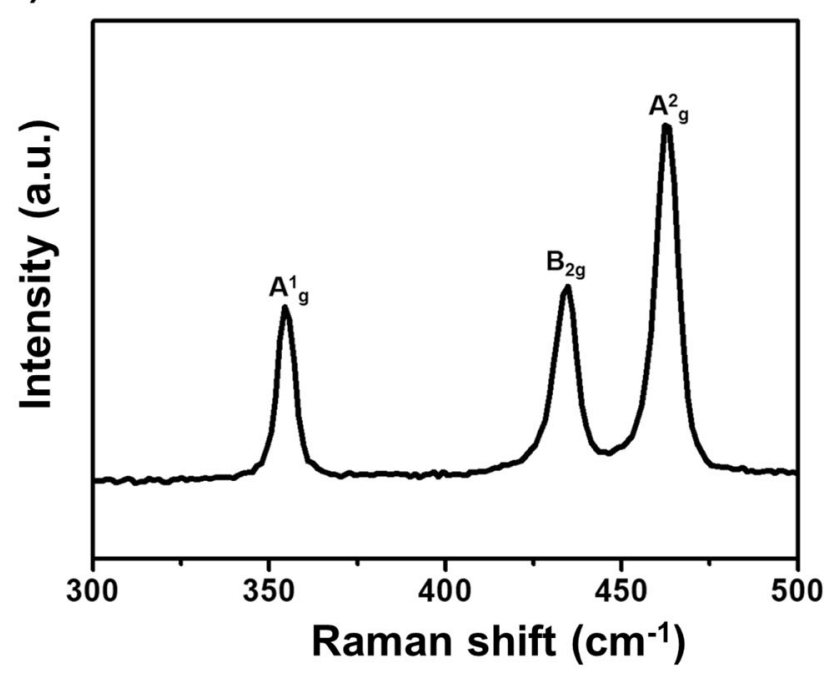


(A)

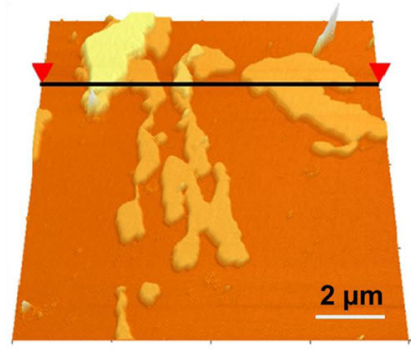

(C)

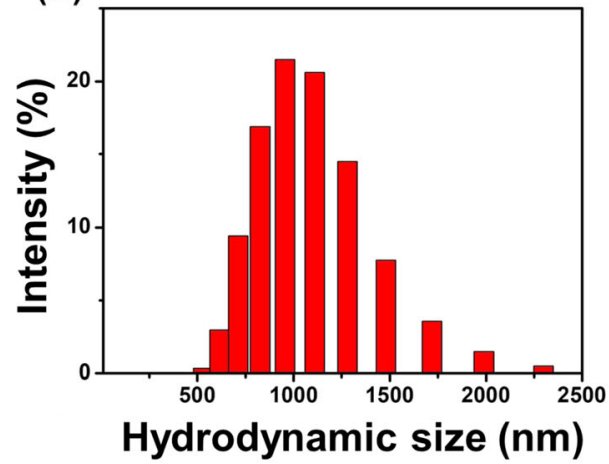

(B)

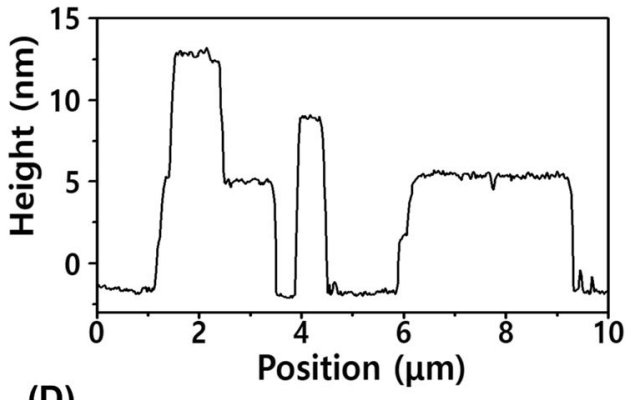

(D)

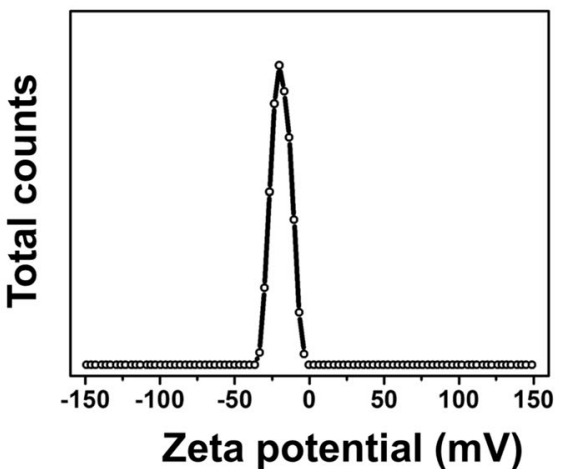

Fig. $\mathbf{2}$ a AFM image and $\mathbf{b}$ corresponding height profile of BPNSs. The black linear line in a marks the position of nanosheets, height of which is measured. Particle Size distribution $\mathbf{c}$ and zeta potential $\mathbf{d}$ of nanosheets in solution

\section{Cell viability}

A decreasing trend in cell viability has been observed in a dose-dependent manner at different periods $24 \mathrm{~h}$ and $48 \mathrm{~h}$ when the fibroblast cells are treated with PBNSs, as shown in Fig. 3a. At $24 \mathrm{~h}$ of study, NIH3T3 and nHDF fibroblast cells have maintained cell viability up to the concentration of $15.6 \mu \mathrm{g} / \mathrm{mL}$ with more than $80 \%$ of viable cells. Fibrosarcoma cells (HT1080) have exhibited $78 \pm 3 \%$ cell viability at $7.8 \mu \mathrm{g} / \mathrm{mL}$. At $48 \mathrm{~h}$ of study, the cell viability of fibrosarcoma cells has been significantly affected when compared to normal fibroblasts (NIH3T3 and nHDF) even at low concentration of nanosheets (Fig. 3b). There was a significant difference in cell viability for fibrosarcoma cells when exposed to nanosheets at the concentration range of $0.3-125 \mu \mathrm{g} / \mathrm{mL}$. The same toxic response has been reflected for NIH3T3 and nHDF cells at the concentration range of $15.6-125 \mu \mathrm{g} / \mathrm{mL}$ and $3.9-125 \mu \mathrm{g} / \mathrm{mL}$ of nanosheets, respectively.

All the cell lines investigated have shown concentration and time-dependent effects on lactate dehydrogenase activity, as shown in Fig. 3b. The low concentrated BPNSs $(0-15.6 \mu \mathrm{g} / \mathrm{mL})$ released a smaller number of $\mathrm{LDH}$ at $24 \mathrm{~h}$ of incubation with cells. The LDH level of NIH3T3 and nHDF fibroblast cells, at $62.5 \mu \mathrm{g} / \mathrm{mL}$ of BPNSs, had increased by 3 and $50 \%$, respectively, and that of HT1080 fibrosarcoma cells increased by more than $100 \%$ at $31.3 \mu \mathrm{g} / \mathrm{mL}$. It has been observed that the amount of the initial LDH release of nHDF fibroblasts and HT1080 fibrosarcoma cells have increased significantly than that of NIH3T3 at $48 \mathrm{~h}$ of study. However, there was a steadiness in the amount of LDH released for all types of cells when the concentration of nanosheets increases above $31.3 \mu \mathrm{g} / \mathrm{mL}$.

The effect of BPNSs on cellular morphology has been observed using optical microscope images at $24 \mathrm{~h}$ incubation of nanosheets with the cells (Fig. $4 \mathrm{a}-\mathrm{c}$ ). The nanosheets that do not permeate the cells have been found aggregated outside the cells. As the concentration of nanosheets increases, there were no changes in the morphology of NIH3T3 cells. At the same time, nHDF and HT1080 cells have shown a decreased cell count at and above $31.3 \mu \mathrm{g} / \mathrm{mL}$ and $7.8 \mu \mathrm{g} / \mathrm{mL}$, respectively.

\section{Discussion}

The respective functional groups of BPNSs have been confirmed from the spectral analyses of FTIR and Raman spectrum. The results were in close agreement with the previously published literature [13-15]. AFM result has informed that the BPNSs produced from liquid exfoliation procedure have contained several layers with different sizes. The Zetasizer analyses revealed that BPNSs have larger hydrodynamic size along with higher polydispersion index, which showed that the nanosheets are agglomerated in solution. However, the average zeta 


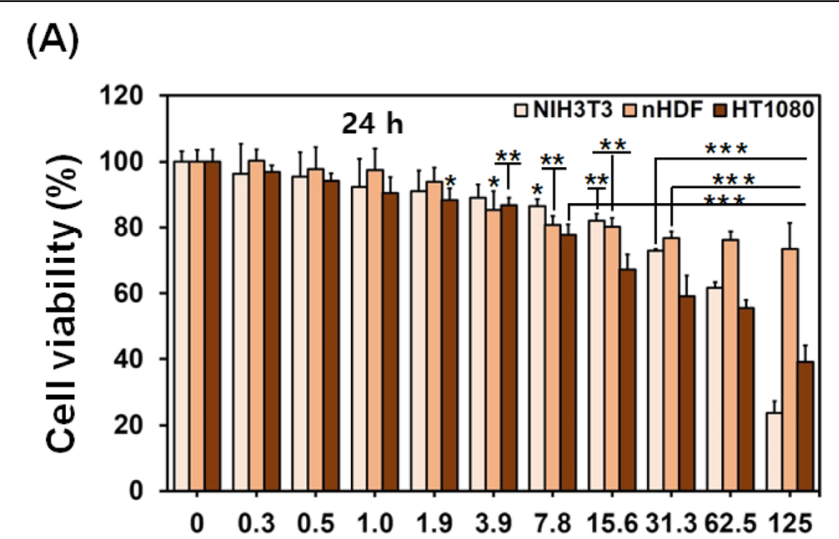

(B)

Concentration of BPNSs $(\mu \mathrm{g} / \mathrm{mL})$
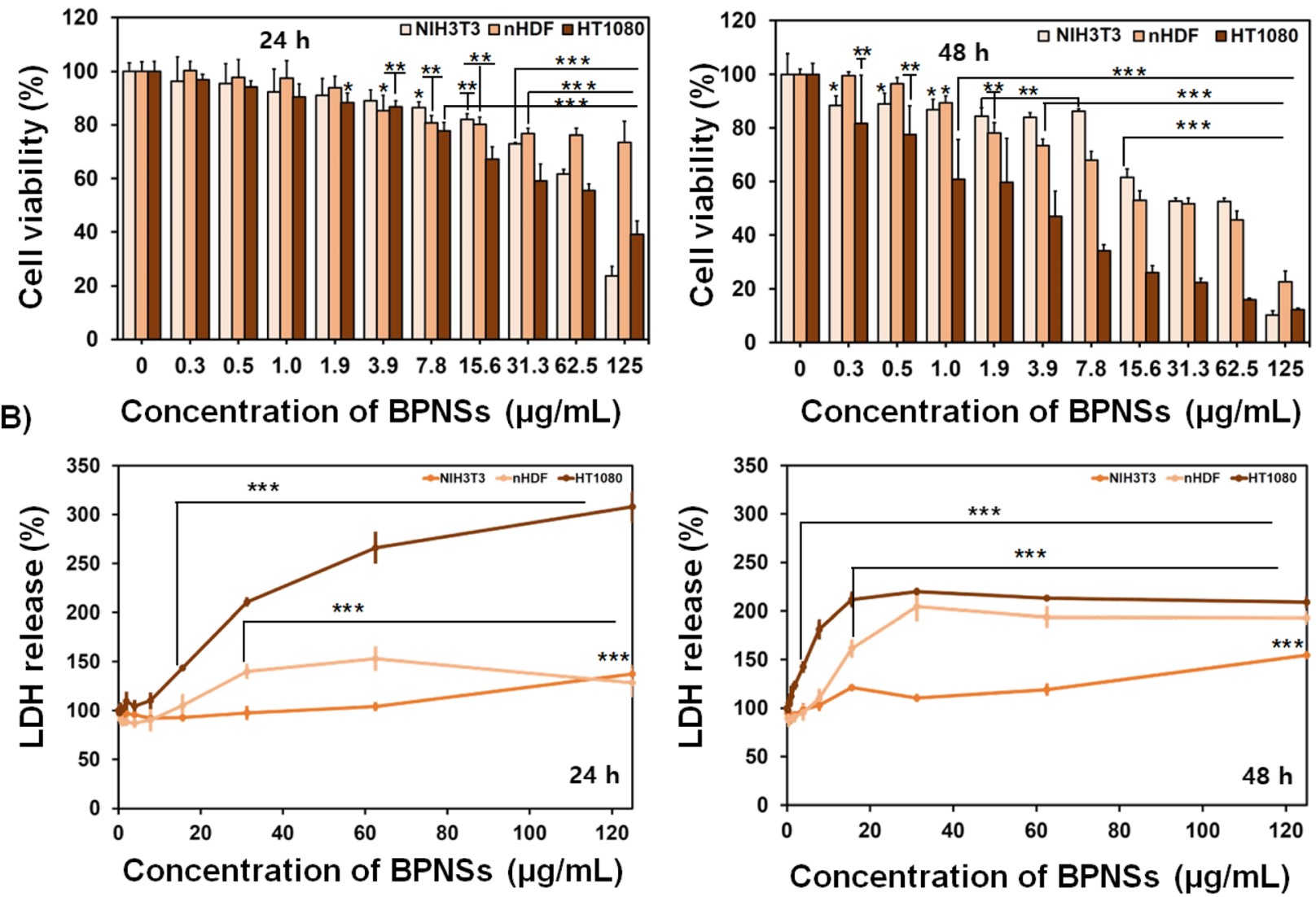

Fig. 3 a Measurement of cell viability (\%) of three different types of cells NIH3T3, nHDF and HT1080 determined by CCK-8 assay. The concentration range of nanosheets (BPNSs) is $0-125 \mu \mathrm{g} / \mathrm{mL}$ and the incubational time periods are $24 \mathrm{~h}$ and $48 \mathrm{~h}$. $\mathbf{b} \mathrm{LDH}$ release profile of the same. The control was the cell line without any additives $(0 \mu \mathrm{g} / \mathrm{mL})$. The data have been represented with standard deviation $(n=3 ; \mathrm{mean} \pm \mathrm{SD}$, ANOVA/Tukey's-test; ${ }^{*} P<0.05$, ${ }^{* *} P<0.01,{ }^{* *} P<0.001$ )

potential value indicates that the nanosheets are moderately stable against further aggregation in solution. The negative sign in zeta potential is due to the $\mathrm{P}-\mathrm{O}$ bond on the surface of nanosheets. It is important to note that the interaction of protein and cell with nanoparticles is majorly dependent on the size and charge of the nanoparticles [16]. The negatively charged nanoparticles have been reported to be preferable for clinical use as they would have longer blood circulation life evading interaction with similarly charged serum proteins [17].

Three different fibroblast cells are investigated to determine cell viability exposing to BPNSs. NIH3T3 and nHDF are normal healthy fibroblast cells whereas HT1080 is a cancerous fibroblast cell line. The normal fibroblast cells are also chosen from different animal sources mouse (NIH3T3) and human (nHDF). Skin and lung are the majorly affected organs for those who work in the places of nanoparticle exposure for prolonged time. We have selected fibroblast cells for the in vitro cytotoxicity studies because they are heterogeneous and dynamic cell lineage presenting with different populations between human tissues [18, 19]. Fibroblast cells can produce extracellular matrix and collagen, which play critical roles in wound healing [20]. Cancerous cells have been found more sensitive towards BPNSs exposure than normal cells, which is evident from cell viability assays. The order of time and concentration-dependent toxic response has been observed as follows, HT1080> nHDF $>$ NIH3T3. CCK-8 assay was carried out to evaluate cell viability through the metabolic activity of mitochondria.

When the cell membrane is damaged, the enzyme $\mathrm{LDH}$ present in the cytoplasm is released to the external medium and hence cytotoxicity of BP particles is correspondent with the disruption of cell membrane [21]. LDH release from the cells nHDF and HT1080 are greater than that of NIH3T3 at $24 \mathrm{~h}$ of the study. Moreover, LDH release from NIH3T3 has been significantly less than that of nHDF and HT1080 at $48 \mathrm{~h}$ of the study, which corroborates with the results of cell viability. As 


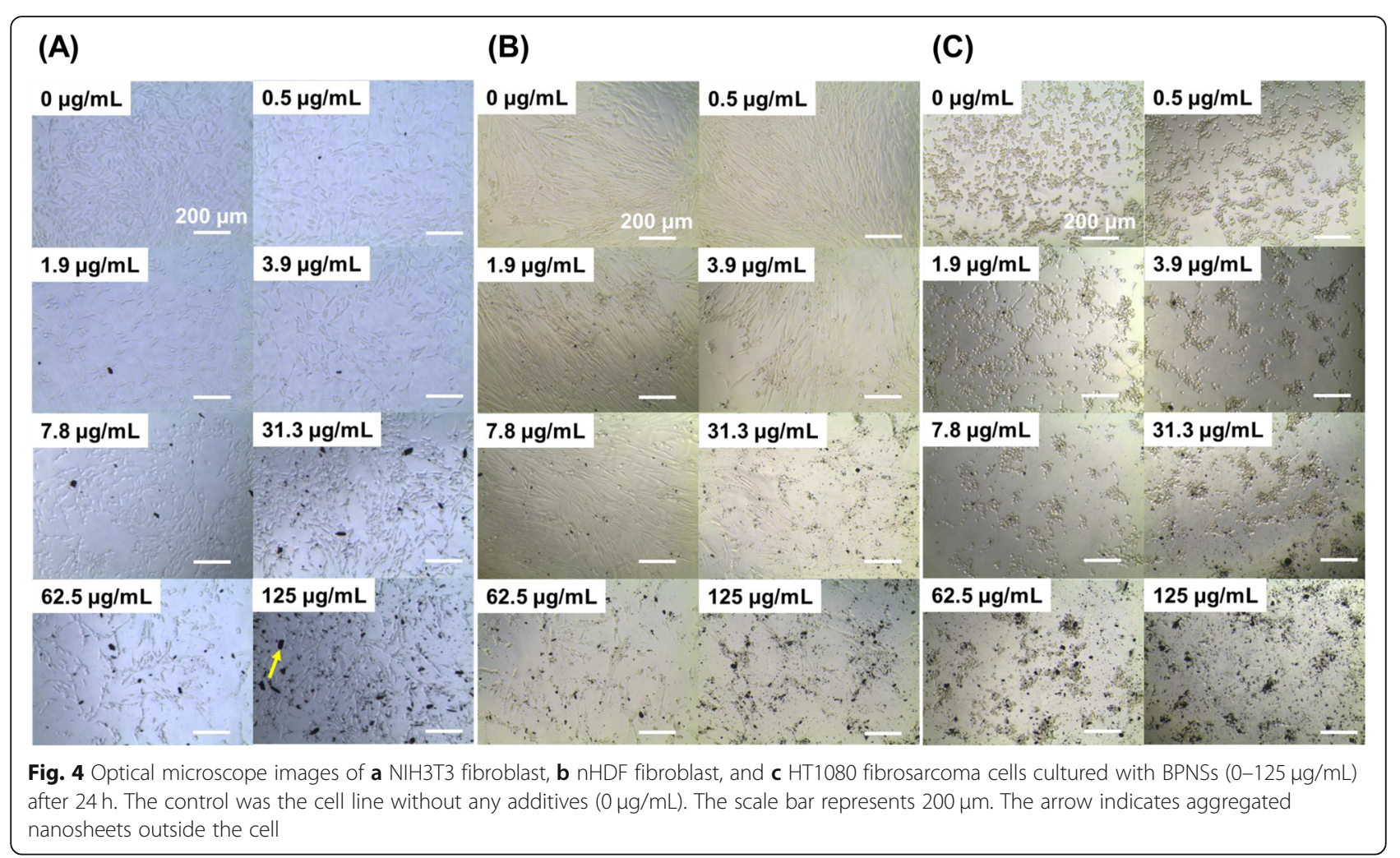

far as cell morphology and cell count are concerned, the optical microscope images describe that morphology of the investigated cells are not affected but the cell counts have been found reduced when exposed to higher concentrated BPNSs $(\geq 31.3 \mu \mathrm{g} / \mathrm{mL})$. As BPNSs affect cellular viability in cancerous fibroblast cells than normal cells in a time and dose-dependent manner, the present work can be further processed to cancer treatment and for in vivo animal studies.

\section{Conclusions}

Black phosphorus nanosheets synthesized using liquid exfoliation procedure were characterized with appropriate physicochemical properties such as identification of functional groups, hydrodynamic size, and zeta potential of the nanosheets. The cytotoxicity of BPNSs has been investigated subjecting different fibroblast cell lines viz. NIH3T3, nHDF, and HT1080. The preliminary study exemplifies that BPNSs has exhibited different level of toxicity depending on cell line type, exposure time and concentration. The salient findings of the work reveal that the nanosheets are more toxic to cancerous HT 1080 cells when compared to its toxic response to normal cells. We conclude that a comprehensive study is still required to elucidate the biological activities of BPNSs through in vitro and in vivo analyses before considering the compound for its biomedical applications including cancer treatment in the future.

\section{Abbreviations}

AFM: Atomic Force Microscope; BPNSs: Black phosphorus nanosheets; CCK8: Cell counting kit-8; FT-IR: Fourier Transform Infrared; LDH: Lactate dehydrogenase; nHDF: Primary human dermal fibroblasts

\section{Acknowledgments}

Not applicable.

\section{Authors' contributions}

S.-J.S. designed the experiments. S.-J.S., Y.B.L., M.S.K., and H.U.L. performed the experiments. I.S.R. and H.J.S. analyzed the data and drafted the manuscript. D.-W.H. supervised the experimental works and improved the manuscript. All the authors have given approval to the final version of the manuscript.

\section{Funding}

This research was supported by the Bio \& Medical Technology Development Program of the National Research Foundation (NRF) funded by the Korean government (MEST, No. 2015M3A9E2028643) and Basic Science Research Program through the National Research Foundation (NRF) of Korea funded by the Ministry of Education (No. 2016R1D1A1B03931076).

\section{Availability of data and materials}

All data generated and analyzed in this study are available from the corresponding author on request.

Ethics approval and consent to participate Not applicable.

\section{Consent for publication}

Not applicable.

\section{Competing interests}

The authors declare that they have no competing interests.

\section{Author details}

'Department of Cogno-Mechatronics Engineering, College of Nanoscience \& Nanotechnology, Pusan National University, Busan 46241, South Korea. 
${ }^{2}$ Monocrystalline Bank Research Institute, Pusan National University, Busan 46241, South Korea. ${ }^{3}$ Advanced Nano-surface Research Group, Korea Basic Science Institute (KBSI), Daejeon 34133, South Korea.

Received: 7 October 2019 Accepted: 22 November 2019

Published online: 29 November 2019

\section{References}

1. Ling $X$, Wang $H$, Huang $S$, Xia F, Dresselhaus MS. The renaissance of black phosphorus. Proc Natl Acad Sci. 2015;112(15):4523-30.

2. Li L, Yu Y, Ye GJ, Ge Q, Ou X, Wu H, Feng D, Chen XH, Zhang Y. Black phosphorus field-effect transistors. Nat Nanotechnol. 2014;9:372.

3. Lee HU, Park SY, Lee SC, Choi S, Seo S, Kim H, Won J, Choi K, Kang KS, Park HG, Kim H-S, An HR, Jeong KH, Lee Y-C, Lee J. Black phosphorus (BP) nanodots for potential biomedical applications. Small. 2016:12(2):214-9.

4. Shin YC, Song S-J, Lee YB, Kang MS, Lee HU, Oh J-W, Han D-W. Application of black phosphorus nanodots to live cell imaging. Biomater Res. 2018;22:31.

5. Fojtu M, Chia X, Sofer Z, Masarik M, Pumera M. Black phosphorus nanoparticles potentiate the anticancer effect of oxaliplatin in ovarian cancer cell line. Adv Funct Mater. 2017;27(36):1701955.

6. Xie H, Shao J, Ma Y, Wang J, Huang H, Yang N, Wang H, Ruan C, Luo Y, Wang QQ, Chu PK, Yu X-F. Biodegradable near-infrared-photoresponsive shape memory implants based on black phosphorus nanofillers. Biomaterials. 2018;164:11-21.

7. Guo Z, Zhang H, Lu S, Wang Z, Tang S, Shao J, Sun Z, Xie H, Wang H, Yu XF, Chu PK. From black phosphorus to phosphorene: basic solvent exfoliation, evolution of raman scattering, and applications to ultrafast photonics. Adv Funct Mater. 2015;25(45):6996-7002.

8. Latiff NM, Teo WZ, Sofer Z, Fisher AC, Pumera M. The cytotoxicity of layered black phosphorus. Chem Eur J. 2015;21(40):13991-5.

9. Gui R, Jin H, Wang Z, Li J. Black phosphorus quantum dots: synthesis, properties, functionalized modification and applications. Chem Soc Rev. 2018;47(17):6795-823.

10. Shao J, Xie H, Huang H, Li Z, Sun Z, Xu Y, Xiao Q, Yu X-F, Zhao Y, Zhang H, Wang H, Chu PK. Biodegradable black phosphorus-based nanospheres for in vivo photothermal cancer therapy. Nat Commun. 2016;7(1):12967.

11. Shen Z, Sun S, Wang W, Liu J, Liu Z, Yu JC. A black-red phosphorus heterostructure for efficient visible-light-driven photocatalysis. J Mater Chem A. 2015;3(7):3285-8.

12. Mu X, Wang JY, Bai X, Xu F, Liu H, Yang J, Jing Y, Liu L, Xue X, Dai H, Liu Q, Sun Y-M, Liu C, Zhang X-D. Black phosphorus quantum dot induced oxidative stress and toxicity in living cells and mice. ACS Appl Mater Interfaces. 2017:9(24):20399-409.

13. Movasaghi Z, Rehman S, ur Rehman DI. Fourier transform infrared (FTIR) spectroscopy of biological tissues. Appl Spectrosc Rev. 2008:43(2):134-79.

14. Sun C, Wen L, Zeng J, Wang Y, Sun Q, Deng L, Zhao C, Li Z. One-pot solventless preparation of PEGylated black phosphorus nanoparticles for photoacoustic imaging and photothermal therapy of cancer. Biomaterials. 2016;91:81-9.

15. Zhang X, Xie H, Liu Z, Tan C, Luo Z, Li H, Lin J, Sun L, Chen W, Xu Z, Xie L, Huang W, Zhang H. Black phosphorus quantum dots. Angew Chem. 2015; 127(12):3724-8.

16. Lord MS, Foss M, Besenbacher F. Influence of nanoscale surface topography on protein adsorption and cellular response. Nano Today. 2010;5(1):66-78.

17. Selestin Raja I, Thangam R, Fathima NN. Polymeric micelle of a gelatinoleylamine conjugate: a prominent drug delivery carrier for treating triple negative breast cancer cells. ACS Appl Bio Mater. 2018;1(5):1725-34.

18. Sorrell JM, Caplan Al. Fibroblast heterogeneity: more than skin deep. J Cell Sci. 2004;117(5):667-75.

19. Cole MA, Quan T, Voorhees JJ, Fisher GJ. Extracellular matrix regulation of fibroblast function: redefining our perspective on skin aging. J Cell Commun Signal. 2018;12(1):35-43.

20. Stylianou A, Gkretsi V, Louca M, Zacharia LC, Stylianopoulos T. Collagen content and extracellular matrix cause cytoskeletal remodelling in pancreatic fibroblasts. J R Soc Interface. 2019:16(154):20190226.

21. Han X, Gelein R, Corson N, Wade-Mercer P, Jiang J, Biswas P, Finkelstein JN, Elder A, Oberdorster G. Validation of an LDH assay for assessing nanoparticle toxicity. Toxicology. 2011;287(1-3):99-104.

\section{Publisher's Note}

Springer Nature remains neutral with regard to jurisdictional claims in published maps and institutional affiliations.

Ready to submit your research? Choose BMC and benefit from:

- fast, convenient online submission

- thorough peer review by experienced researchers in your field

- rapid publication on acceptance

- support for research data, including large and complex data types

- gold Open Access which fosters wider collaboration and increased citations

- maximum visibility for your research: over $100 \mathrm{M}$ website views per year

At BMC, research is always in progress.

Learn more biomedcentral.com/submissions 